\title{
THE USE OF HEPATOPROTECTORS IN THE PHARMACOTHERAPY OF COMORBID VASCULITIS WITH CRYOGLOBULINEMIC SYNDROME
}

\author{
Ihor Hayduchok \\ Candidate of Medical Sciences, Associate Professor, Lviv Medical Institute, Ukraine \\ e-mail: ihor.hayduchok@ukr.net, orcid.org/0000-0003-2897-8417
}

\section{Summary}

The article presents studies concerning the pharmaceutical therapy and provision among patients with comorbid vasculitis with cryoglobulinemic syndrome. Information from various authors on subject and particularities of its treatment was analyzed. While conducting literature review, used pharmaceutical and economic, organizational and legal, forensic and pharmaceutical approaches and methodology in studying of particularities of pharmaceutical therapy and provision among patients with above-mentioned illness. ABC/VEN analysis was used in study to select the most effective and safe drugs, while keeping in mind treatment costs in Ukraine. The matrix of the consolidated ABC/VEN analysis of drugs for treatment of mentioned patients with comorbid vasculitis in Ukraine using hepatoprotectors was developed during the study. Further researches needed in order to implement into the state programs for pharmaceutical therapy and provision among patients with comorbid vasculitis with cryoglobulinemic syndrome. Importance in making appropriate administrative and managerial decisions while detecting the comorbid vasculitis in order to improve the use of drugs in healthcare facilities was proved.

Keywords: medicine, vasculitis, comorbidity, pharmacotherapy, pharmacoeconomic, ATC-code A16AA02.

DOI: https://doi.org/10.23856/4430

\section{Introduction}

Vasculitis is a scattered collection of rare diseases characterized by inflammation of the blood vessel walls. It can cause damage to a number of different organs and tissues, leading to a wide range of clinical manifestations depending on the affected part of the vascular tree. The reasons are not fully known. Over time, it can damage organs and blood vessels (Vasculitis, 2017).

The different types of vasculitis are grouped according to the size of the affected blood vessels. For example, vasculitis of large vessels, giant cell arteritis, primarily affects elderly patients, manifests itself in headaches and pain in the jaw while eating. Vasculitis affecting medium-sized vessels includes Kawasaki disease et al. Small vessel vasculitis includes immunoglobulin A vasculitis, cryoglobulinemia vasculitis, and hypersensitivity vasculitis. Vasculitis can be primary and autoimmune in nature, or comorbid with immune-dependent syndromes, infection, drugs, or cancer (Fellner, 2016).

The most common autoimmune vasculitis is the subgroup associated with antineutrophilic cytoplasmic antibodies (AAV), which predominantly affect small to medium sized blood vessels in the body. AAV - associated vasculitis, although rare, must be diagnosed and treated early, or it can rapidly progress to organ failure and death. Patients can present with a wide range of symptoms, from acute manifestations with rapidly progressive liver disease, kidney disease, and pulmonary hemorrhage, to subtle nasal or hearing problems (Vincent et al., 2015). 
AAV-associated vasculitis is more common in older adults. The peak age of disease onset is 65-74 years, and the annual incidence is 20 cases per million population. The cause of AAV is unknown, but a genetic predisposition is believed to exist. Patients with AAV may experience general symptoms of inflammation such as fever, malaise, weight loss, muscle and joint pain; these nonspecific symptoms often lead to late diagnosis. The skin is affected by a purple rash on the lower extremities. The liver and kidneys (among 90\% of patients), lungs, eyes, intestines, and the peripheral nervous system are often affected (Marushko, 2020).

The main problems of pharmacotherapy are the elimination of the chronic damage caused by the disease and the toxicity of the treatment. The risk of treatment-related illnesses increases over time and may include cardiovascular disease, diabetes, osteoporosis, and cancer. Mortality is highest during the first year after diagnosis, during which infection is the leading cause of death. Cardiovascular disease and cancer become more common after the first year of life. Between $20 \%$ and $40 \%$ of AAV patients become dialysis dependent within three to five years. For many patients, fatigue significantly reduces the quality of life. There is no cure for $\mathrm{AAV}$, so the goal of treatment is to achieve and maintain remission (defined as the absence of disease activity). Treating comorbid vasculitis is challenging. In many cases, vasculitis is treated as a chronic condition. Pharmacotherapy options vary according to the form of vasculitis. It is important to note that when vasculitis is treated, the immune system is suppressed and the risk of infections is increased.

\section{Pharmacoeconomic studies in the pharmacotherapy of comorbid vasculitis with cryoglobulinemic syndrome}

Immune-dependent process due to the presence in the serum of pathological proteins cryoglobulins, is accompanied by the development of cryoglobulinemic syndrome. Cryoglobulins are reverse precipitated at temperatures below $37^{\circ} \mathrm{C}$ in vessels of small and medium caliber, which often leads to the development of comorbid vasculitis.

According to statistics, cryoglobulinemic syndrome is found among $46.7 \%$ of patients with comorbid vasculitis (Kuzmina, 2015).

Careful monitoring of side effects is required with any treatment for vasculitis. Because there is a high risk of infection, screening for infection (including tuberculosis) should be carefully considered before initiating immunosuppressive therapy. Patients should also be advised to be vaccinated against influenza and pneumococcus. After starting treatment, urea and electrolytes, general blood tests and liver function tests should be checked regularly, usually first every one or two weeks, although this depends on the type and intensity of therapy. Patients in remission receive maintenance treatment for at least 12 months. Relapses are common, with $50 \%$ of patients having relapses within five years (Vincent et al., 2015).

Systemic vasculitis is one of the most severe forms of chronic comorbid pathology, which is complicated by pulmonary hemorrhage, myocardial infarction, renal failure, hepatobiliary and neurological disorders, limb gangrene (Marushko, 2020).

The stages of diagnosis of comorbid vasculitis include: identification of clinical symptoms and syndromes that suggest the presence of vasculitis; exclusion of other processes that mimic primary vasculitis; assessment of the prevalence of the process in the vessels (in the process of computer angiographic examination); determination in accordance with the qualification criteria of the variant of vasculitis (confirmed by biopsy results) (Kuzmina, 2015).

Modern views on the main, more common comorbid vasculitis, their pathogenesis, clinical picture, methods of diagnosis and evaluation of clinical manifestations from the standpoint 
of a primary care physician - general (family practice) are considered. Given the plan of examination of the patient, laboratory and instrumental changes at the main vasculitis, methods of treatment (Krivenko et al., 2018).

The US vasculitis pharmaceutical market is expected to grow at a rate of $3.8 \%$ per year for the decade from 2014 to 2024, reaching sales of \$316 million (Fellner, 2016).

With the spread of the coronavirus pandemic (Shapovalova et al., 2020), the role of pharmacotherapy of systemic vasculitis with cryoglobulinemic syndrome among patients with dual health disorders and among patients with systemic diseases (control regime of antibacterial drugs for pharmacotherapy of coronavirus disease (COVID-19) among patients with dual disorders: newsletter) becomes very relevant (Hayduchok et al., 230-2020; Hayduchok et al., 225-2020).

Despite numerous publications on COVID-19, at present, conceptual thinking of the problem is only at a nascence stage. Treatment of patients with ANCA-associated systemic vasculitis (AAV) during the COVID-19 pandemic is one of the relevant issues. Further analysis of COVID-19 in patients with AAV is important (Beketova, 2019).

The experience of the USA concerning and organization of healthcare system for the pharmaceutical provision for privileged categories of citizens (Shapovalov (Jr.) et al., 2019) was written earlier; forensic and pharmaceutical analysis of addictive morbidity because of the use of psychoactive substances in Ukraine (Shapovalov (Jr.) et al., 2020); experience of Great Britain in the organization of healthcare system for pharmaceutical provision with medicines for privileged categories of citizens (Shapovalov (Jr.) et al., 2019).

Treatment of cryoglobulinemic syndrome remains a challenge. In secondary cryoglobulinemia, treatment of the underlying disease is crucial. In comorbid vasculitis on the background of mixed cryoglobulinemia, the treatment strategy is based on antiviral, anti-inflammatory and immunosuppressive pharmacotherapy.

The objectives of pharmacotherapy for cryoglobulinemic syndrome include reducing the level of immunoglobulins and elimination of antigen by phagocytosis through the liver, spleen and the like.

The first problem can be solved by using immunosuppressive pharmacotherapy and hepatoprotectors; the second task - through the use of antiviral therapy, which reduces the concentration of antigens in the body.

Today it is important to use modern, effective and safe hepatoprotectors for pharmacotherapy of comorbid vasculitis with cryoglobulinemic syndrome. Pharmacoeconomic approaches, in particular $\mathrm{ABC} / \mathrm{VEN}$ analysis, are used to select effective and safe drugs.

Purpose of the research - the use of hepatoprotectors in the pharmacotherapy of comorbid vasculitis with cryoglobulinemic syndrome based on pharmacoeconomic approaches with $\mathrm{ABC} / \mathrm{VEN}$ analysis.

Material and methods. According to the clinical and pharmacological group for pharmacotherapy of comorbid vasculitis with cryoglobulinemic syndrome were selected hepatoprotectors that have the diagnostic code of the ATC-Classification (ATC): A "Agents affecting the digestive system and metabolism"; A16 "Other agents affecting the digestive system and metabolic processes", A16A "Other agents affecting the digestive system and metabolic processes", A16AA "Amino acids and their derivatives" by INN Ademetionine (ATC-classification, 2020).

As hepatoprotectors was proposed drug according to INN Ademetionine ATC-code A16AA02 at a dose of $1000 \mathrm{mg} 2$ times a day for 21 days in the form of three courses with an interval between courses of 1 month. 
Ademetionine is used as a hepatoprotector in diseases according to ICD-10: B - some infectious and parasitic diseases; $\mathrm{F}$ - mental and behavioral disorders; $\mathrm{K}$ - diseases of the digestive system; $\mathrm{O}$ - complications of pregnancy, childbirth.

To assess the cost of pharmacotherapy of comorbid vasculitis with cryoglobulinemic syndrome $\mathrm{ABC}$ analysis was performed as a tool to study the cost of purchasing drugs. ABC analysis involves the distribution of drugs from the most to the least expensive depending on their share among the indicators of the general purpose of drugs (Management Science for Health, 2012; Shapovalov (Jr.) et al., 2018).

To assess the effectiveness of drug use, a VEN analysis was performed to classify drugs into categories V (vital), E (essential) and $\mathrm{N}$ (non-essential), taking into account regulatory documents: medical care standards, clinical protocols, State Form of Medicines (Order of the Ministry of Health of Ukraine, 2020), National List of Essential Medicines (National list of basic medicines, 2009) and principles of evidence-based medicine (evidence of efficacy, quality, safety, economy, affordability). The following approach was used in this analysis: the division of drugs into categories V - "Vital" (vital); E - "Essential" (necessary) and N - "Non-essential" (secondary, unimportant).

Study Design is based on pharmacoeconomic, organizational and legal (Shapovalov (Jr.) et al., 2018), forensic and pharmaceutical (Shapovalova et al., 2021) approaches to pharmacotherapy with using literature review.

The USAID delivery project logistics indicator assessment tool was employment to determine the sample size of health facilities. It recommends a minimum of $15 \%$ of the total health facilities inclusion (Snow, 2005).

The research of the article is a fragment of research works of Lviv Medical Institute LLC on the topic "Improvement of the drug circulation system during pharmacotherapy on the basis of evidentiary and forensic pharmacy, organization, technology, biopharmacy and pharmaceutical law" (state registration number 0120U105348, terms 2021-2026), Kharkiv Medical Academy of Postgraduate Education on "Improving the organizational and legal procedure for providing patients with drugs from the standpoint of forensic pharmacy, organization and management of pharmacy" (state registration number 0116U003137, terms 2016-2020) and "Pharmaceutical and medical law: integrated approaches to the system of drug circulation from the standpoint of forensic pharmacy and organization of pharmaceutical business" (state registration number D/21U000031, terms 2021-2026) (Shapovalov (Jr.) et al., 2017).

In the International Classification of Diseases of the 10th revision, systemic vasculitis is a disease of the musculoskeletal system (class XIII), where 12 blocks are identified. For example, M30 - nodular polyarteritis and related conditions; M31 - other necrotizing vasculopathies; M35 - other systemic connective tissue lesions. Small vessel vasculitis includes immunoglobulin A vasculitis, cryoglobulinemia vasculitis, and hypersensitivity vasculitis (Fellner, 2016).

Vasculitis Shenlein-Genoha has the code of the International Classification of Diseases 10 edition D69 "Purpura and other hemorrhagic conditions" class "Diseases of the blood, blood-forming organs and certain disorders involving immune mechanisms." The code of the International Classification for Primary Care-2 is B83 (Hayduchok et al., 64-2021).

Shenlein-Genoch vasculitis is a hemorrhagic vasculitis with IgA-immune deposits that affects small vessels (capillaries, venules, arterioles).

In international treatment protocols, Shenlein-Genoch vasculitis is called IgA-associated vasculitis (Fellner, 2016).

The pharmacotherapy of comorbid vasculitis includes drugs included in clinical international and national protocols: Heparin, Acetylsalicylic acid, Prednisolone, Ciclosporin, 
Paracetamol, Hydroxychloroquine, Ergocalciferol, Azithromycin, Pancreatin (International Guideline 00653, 2016; International Guidelines 00449, 2017).

According to clinical and pharmacological analysis, the largest share of drugs for pharmacotherapy of comorbid vasculitis $(22.22 \%)$ have diagnostic codes of ATC classification: A - "Drugs that affect the digestive system and metabolism" and N - "Drugs that affect the nervous system".

With the personal participation of the author, a scheme of pharmacotherapy with the use of hepatoprotectors for the treatment of underlying and comorbid diseases was developed.

Drug therapy of comorbid vasculitis with cryoglobulinemic syndrome included the use of hepatoprotectors according to the INN Ademetionine ATC-code A16AA02.

At a later stage, marketing and pharmacoeconomic studies of drugs were performed according to INN Ademetionine ATC-code A16AA02 (Table 1).

Table 1

Marketing - analysis of drugs according to INN Ademetionine by ATC-code A16AA02 for comorbid vasculitis with cryoglobulinemic syndrome

\begin{tabular}{|c|c|c|c|}
\hline No & $\begin{array}{l}\text { Trade name / } \\
\text { Manufacturer }\end{array}$ & $\begin{array}{l}\text { Dosage form, strength, } \\
\text { amount per unit }\end{array}$ & $\begin{array}{c}\text { Registration } \\
\text { certificate Term }\end{array}$ \\
\hline 1 & 2 & 3 & 4 \\
\hline 1. & $\begin{array}{l}\text { Hepamethion } \\
\text { PJSC "Kyivmedpreparat" (man- } \\
\text { ufacturer of lyophilisate, respon- } \\
\text { sible for the release of a batch of } \\
\text { finished drug), Ukraine } \\
\text { PJSC "Halychpharm" (solvent } \\
\text { manufacturer), Ukraine }\end{array}$ & $\begin{array}{l}\text { Lyophilisate for solution for } \\
\text { injection of } 400 \mathrm{mg}, 5 \text { vials } \\
\text { of lyophilisate complete with } \\
5 \text { ampoules of solvent (L-lysine, } \\
\text { sodium hydroxide, water for } \\
\text { injections) of } 5 \mathrm{ml} \text { in a contour } \\
\text { honeycomb package; } 1 \text { contour } \\
\text { honeycomb package in a card- } \\
\text { board pack }\end{array}$ & $\begin{array}{l}\text { UA/15978/01/01 } \\
12.05 .201712 .05 .2022\end{array}$ \\
\hline 2. & $\begin{array}{l}\text { Heptral } \\
\text { Famar A.V.E. Alimos Plant 63, } \\
\text { street Ag. Dimitriou (manufacture, } \\
\text { primary packaging, quality control } \\
\text { and batch of solvent in bulk), } \\
\text { Greece } \\
\text { Delpharm Saint-Remy (manufac- } \\
\text { ture, primary packaging and qual- } \\
\text { ity control of lyophilised powder; } \\
\text { secondary packaging, quality con- } \\
\text { trol and batch release of finished } \\
\text { medicinal product), France } \\
\text { Biologisi Italy Laboratories S.R.L. } \\
\text { (manufacture, primary packaging } \\
\text { and quality control of lyophilised } \\
\text { powder; secondary packaging, } \\
\text { quality control and batch release } \\
\text { of finished medicinal product; } \\
\text { production, primary packaging and } \\
\text { quality control of solvent), Italy }\end{array}$ & $\begin{array}{l}\text { Lyophilized powder for solution } \\
\text { for injection of } 500 \mathrm{mg}, 5 \text { glass } \\
\text { vials of lyophilized powder } \\
\text { and } 5 \text { ampoules with solvent } \\
\text { (L-lysine, sodium hydroxide, } \\
\text { water for injections) of } 5 \mathrm{ml} \text { in } \\
\text { a contour honeycomb package } \\
\text { sealed with aluminum foil; } 1 \\
\text { contour honeycomb package in } \\
\text { a cardboard box }\end{array}$ & $\begin{array}{l}\text { UA/6993/02/02 } \\
\text { Unlimited from } \\
24.02 .2021\end{array}$ \\
\hline
\end{tabular}


Table 1 (Continued)

\begin{tabular}{|c|c|c|c|}
\hline 1 & 2 & 3 & 4 \\
\hline 3. & $\begin{array}{l}\text { Heptral } \\
\text { Famar Legl (manufacture, primary } \\
\text { packaging and quality control of } \\
\text { lyophilised powder; secondary } \\
\text { packaging, quality control and } \\
\text { batch release of finished medicinal } \\
\text { product), France } \\
\text { Famar A.V.E. Alimos Plant 63, } \\
\text { street Ag. Dimitriou (manufacture, } \\
\text { primary packaging, quality control } \\
\text { and batch of solvent in bulk), } \\
\text { Greece } \\
\text { Biologisi Italy Laboratories S.R.L. } \\
\text { (manufacture, primary packaging } \\
\text { and quality control of lyophilised } \\
\text { powder; secondary packaging, } \\
\text { quality control and batch release of } \\
\text { finished medicinal product), Italy }\end{array}$ & $\begin{array}{l}\text { Lyophilized powder for solution } \\
\text { for injection of } 400 \mathrm{mg}, 5 \text { glass } \\
\text { vials of lyophilized powder } \\
\text { and } 5 \text { ampoules with solvent } \\
\text { (L-lysine, sodium hydroxide, } \\
\text { water for injections) in } 5 \mathrm{ml} \text { in } \\
\text { a contour honeycomb package; } \\
1 \text { contour honeycomb package } \\
\text { in a cardboard box }\end{array}$ & $\begin{array}{l}\text { UA/6993/02/01 } \\
\text { Unlimited from } \\
19.05 .2017\end{array}$ \\
\hline 4. & $\begin{array}{l}\text { Hep-art } \\
\text { JSC “Farmak", Ukraine }\end{array}$ & $\begin{array}{l}\text { Enteric tablets, } 400 \mathrm{mg} \text {; } 4 \text { tab- } \\
\text { lets in a blister; } 5 \text { blisters in } \\
\text { a pack }\end{array}$ & \begin{tabular}{|l|}
$\mathrm{UA} / 18365 / 01 / 01$ \\
12.10 .202012 .10 .2025
\end{tabular} \\
\hline 5. & $\begin{array}{l}\text { Rehol } \\
\text { LLC NVF “MICROCHEM", } \\
\text { Ukraine }\end{array}$ & $\begin{array}{l}\text { Enteric tablets of } 400 \mathrm{mg}, 8 \text { tab- } \\
\text { lets in a blister, } 1 \text { or } 3 \text { blisters in } \\
\text { a pack of cardboard; } 10 \text { tablets } \\
\text { in a blister; } 2 \text { blisters in a pack } \\
\text { of cardboard }\end{array}$ & \begin{tabular}{|l}
$\mathrm{UA} / 17043 / 01 / 01$ \\
20.11 .201820 .11 .2023
\end{tabular} \\
\hline 6. & $\begin{array}{l}\text { Heptral } \\
\text { Abbvi S.r.l., Italy }\end{array}$ & $\begin{array}{l}\text { Enteric tablets of } 500 \mathrm{mg} \text { of } \\
10 \text { tablets in a blister; } 2 \text { blisters } \\
\text { in a cardboard box }\end{array}$ & $\begin{array}{l}\text { UA/6993/01/02 } \\
\text { Unlimited from } \\
26.01 .2021 \\
\end{array}$ \\
\hline 7. & $\begin{array}{l}\text { Heptral } \\
\text { Abbvi S.r.l., Italy }\end{array}$ & $\begin{array}{l}\text { Enteric tablets of } 400 \mathrm{mg}, \\
10 \text { tablets in a blister; } 1 \text { or } \\
2 \text { blisters in a cardboard package }\end{array}$ & $\begin{array}{l}\text { UA/6993/01/01 } \\
\text { Unlimited from } \\
19.05 .2017\end{array}$ \\
\hline
\end{tabular}

For pharmacotherapy of comorbid vasculitis with cryoglobulinemic syndrome tablets occupy $57 \%$ of prescriptions, lyophilized powder for solution for injection $-43 \%$.

The studied drugs in $57 \%$ have an unlimited validity of registration certificates.

Ranking of manufacturers of studied drugs: Ukraine $-43 \%$; Italy $-57 \%$.

The next task was to conduct pharmacoeconomic research through ABC/VEN analysis, which involves the distribution of drugs by the cost of pharmacotherapy and evaluation of the effectiveness of drug use in a health care facility (tables 2, 3).

According to the results of $\mathrm{ABC}$ analysis, category A included drugs, the use of which was equal to $80.34 \%$ of the total rate of use; to category $\mathrm{B}-14.68 \%$, and to category $\mathrm{C}-4.99 \%$.

Category A included four drugs: Heptral (Lyophilized powder for solution for injection of $500 \mathrm{mg}$ ); Heptral (Lyophilized powder for solution for injection of $400 \mathrm{mg}$ ); Hepamethion; Heptral (Enteric tablets of $500 \mathrm{mg}$ ). The cost of one dose is $465,55 \mathrm{UAH}$, which is $80.34 \%$ of the total cost of pharmacotherapy. 
Table 2

ABC analysis of drugs according to INN Ademetionine code A16AA02 for pharmacotherapy of comorbid vasculitis with cryoglobulinemic syndrome

\begin{tabular}{|c|l|c|c|c|}
\hline No. & \multicolumn{1}{|c|}{ Trade name } & $\begin{array}{c}\text { Dose costs, } \\
\text { UAH }\end{array}$ & Share (\%) & $\begin{array}{c}\text { ABC } \\
\text { category }\end{array}$ \\
\hline 1. & $\begin{array}{l}\text { Heptral (Lyophilized powder } \\
\text { for solution for injection of 500 mg) }\end{array}$ & 153,40 & 26,47 & $\mathrm{~A}$ \\
\hline 2. & $\begin{array}{l}\text { Heptral (Lyophilized powder } \\
\text { for solution for injection of 400 mg) }\end{array}$ & 135,00 & 23,30 & $\mathrm{~A}$ \\
\hline 3. & Hepamethion & 115,80 & 19,98 & $\mathrm{~A}$ \\
\hline 4. & Heptral (Enteric tablets of 500 mg) & 61,35 & 10,59 & $\mathrm{~A}$ \\
\hline & Total for category A & $\mathbf{4 6 5 , 5 5}$ & $\mathbf{8 0 , 3 4}$ & \\
\hline 5. & Heptral (Enteric tablets of 400 mg) & 55,30 & 9,54 & $\mathrm{~B}$ \\
\hline 6. & Rehol & 29,75 & 5,13 & $\mathrm{~B}$ \\
\hline & Total for category B & $\mathbf{8 5 , 0 5}$ & $\mathbf{1 4 , 6 8}$ & \\
\hline & Total for categories AB : & $\mathbf{5 5 0 , 6}$ & $\mathbf{9 5 , 0 1}$ & $\mathrm{C}$ \\
\hline 7. & Hep-art & 28,90 & 4,99 & \\
\hline & Total for category C: & $\mathbf{2 8 , 9 0}$ & $\mathbf{4 , 9 9}$ & \\
\hline & Total for categories ABC: & $\mathbf{5 7 9 , 5 0}$ & $\mathbf{1 0 0 , 0 0}$ & \\
\hline
\end{tabular}

Category B included two drugs: Heptral (Enteric tablets of $400 \mathrm{mg}$ ) and Rehol. The cost of one dose of category B drugs is 80.05 UAAN (14.68\%).

One drug (Hep-art) is designed for category C. The cost is 28.90 UAAN per unit dose $(4.99 \%)$.

Table 3

VEN-analysis of drugs according to INN Ademetionine code A16AA02 for pharmacotherapy of comorbid vasculitis with cryoglobulinemic syndrome

\begin{tabular}{|c|l|c|}
\hline No & \multicolumn{1}{|c|}{ Trade name } & \multicolumn{1}{|c|}{ VEN category } \\
\hline 1. & $\begin{array}{l}\text { Heptral (Lyophilized powder for solution for injection } \\
\text { of 500 mg) }\end{array}$ & E \\
\hline 2. & $\begin{array}{l}\text { Heptral (Lyophilized powder for solution for injection } \\
\text { of 400 mg) }\end{array}$ & E \\
\hline 3. & Hepamethion & E \\
\hline 4. & Heptral (Enteric tablets of $500 \mathrm{mg})$ & $\mathrm{E}$ \\
\hline 5. & Heptral (Enteric tablets of $400 \mathrm{mg})$ & $\mathrm{E}$ \\
\hline 6. & Rehol & $\mathrm{E}$ \\
\hline 7. & Hep-art & \multicolumn{2}{|c|}{} \\
\hline
\end{tabular}

According to the results of VEN analysis, it was found that all seven drugs - Heptral (Lyophilized powder for solution for injection of $500 \mathrm{mg}$ ); Heptral (Lyophilized powder for solution for injection of $400 \mathrm{mg}$ ); Hepamethion; Heptral (Enteric tablets of $500 \mathrm{mg}$ ); Heptral (Enteric tablets of $400 \mathrm{mg}$ ); Rehol; Hep-art belong to category E.

Categories V (vital) and N (non-essential) did not include any drugs.

The distribution of VEN analysis of investigational drugs by INN Ademetionine code A16AA02 comorbid vasculitis with cryoglobulinemic syndrome is shown in Fig. 1. 


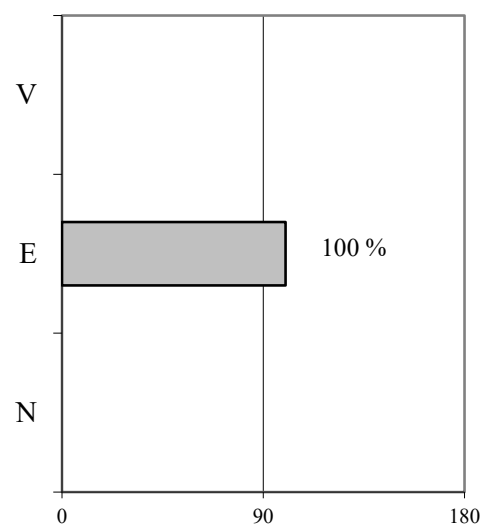

Vital: -

Essential: Heptral (Lyophilized powder for solution for injection of $500 \mathrm{mg}$ ), Heptral (Lyophilized powder for solution for injection of $400 \mathrm{mg}$ ), Hepamethion, Heptral (Enteric tablets of $500 \mathrm{mg}$ ), Heptral (Enteric tablets of $400 \mathrm{mg}$ ), Rehol, Hep-art

Non-essential: -

Fig. 1. Distribution according to the results of VEN analysis of studied drugs according to INN Ademetionine code A16AA02 for comorbid vasculitis with cryoglobulinemic syndrome

Tested drugs in 100\% (Heptral, Lyophilized powder for solution for injection of $500 \mathrm{mg}$; Heptral, Lyophilized powder for solution for injection of $400 \mathrm{mg}$; Hepamethion; Heptral, Enteric tablets of $500 \mathrm{mg}$; Heptral, Enteric tablets of $400 \mathrm{mg}$; Rehol; Hep-art) are included in pharmacotherapy as Essential (category E).

Based on the ABC/VEN analysis, a matrix of the consolidated ABC/VEN analysis was developed (Table 4).

Table 4

Matrix of the consolidated ABC-VEN-analysis of drugs according to INN Ademetionine under the code A16AA02 for comorbid vasculitis with cryoglobulinemic syndrome

\begin{tabular}{|c|c|c|c|c|c|c|c|c|c|}
\hline \multirow{3}{*}{$\begin{array}{c}\text { Drugs } \\
\text { categories }\end{array}$} & \multirow{3}{*}{$\begin{array}{c}\text { Drugs } \\
\text { quantity }\end{array}$} & & & \multirow{3}{*}{$\begin{array}{c}\text { Drugs } \\
\text { quantity }\end{array}$} & & & \multirow{3}{*}{$\begin{array}{c}\text { Drugs } \\
\text { quantity }\end{array}$} & \multirow{2}{*}{\multicolumn{2}{|c|}{ 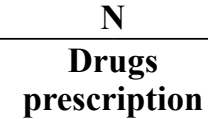 }} \\
\hline & & \multicolumn{2}{|c|}{$\begin{array}{c}\text { Drugs } \\
\text { prescription }\end{array}$} & & \multicolumn{2}{|c|}{$\begin{array}{c}\text { Drugs } \\
\text { prescription }\end{array}$} & & & \\
\hline & & UAH & $\%$ & & UAH & $\%$ & & UAH & $\%$ \\
\hline A & - & - & - & 4 & 465,55 & 80,34 & - & - & - \\
\hline $\mathrm{B}$ & - & - & - & 2 & 85,05 & 14,68 & - & - & - \\
\hline $\mathrm{C}$ & - & - & - & 1 & 28,90 & 4,99 & - & - & - \\
\hline Total: & - & - & - & 7 & 579,50 & 100,00 & - & - & - \\
\hline
\end{tabular}

Category E drugs took the most prescriptions (100\%).

The share of costs that accounted for drugs in the niches of the matrix.

The niche of the A/E matrix took 80.34\%. Examples: Heptral (Lyophilized powder for solution for injection of $500 \mathrm{mg}$ ) / Heptral (Enteric tablets of $500 \mathrm{mg}$ ). This niche of the matrix took the largest indicator of the total cost of pharmacotherapy and doctor's appointments.

Niches of the matrix $\mathrm{A} / \mathrm{V}-0 \%$ and $\mathrm{A} / \mathrm{N}-0 \%$.

The niche of the B/E matrix was 14.68\%. Drugs: Heptral (Enteric tablets of $400 \mathrm{mg}$ ) / Rehol.

Niches of the matrix B / V $-0 \%$ and $\mathrm{B} / \mathrm{N}-0 \%$.

Drugs in the niches of the matrix in category $\mathrm{C}$ had the following indicators: $\mathrm{C} / \mathrm{E}-$ 4.99\% Hep-art; C/N - 0\%; C/V - 0\%. 


\section{Conclusions and suggestions}

The relevance and necessity of the chosen research topic as a result of a review of the scientific literature on the pharmacotherapy of comorbid vasculitis with cryoglobulinemic syndrome are substantiated.

Clinical and pharmacological analysis of pharmacotherapy of comorbid vasculitis was performed. It is estimated that the drugs under the ATC code A "Drugs that affect the digestive system and metabolism" had a share of $22.22 \%$.

Marketing research of drugs according to INN Ademetionine under code A16AA02 for comorbid vasculitis with cryoglobulinemic syndrome by assortment, countries-manufacturers, dosage forms, registration certificates was carried out.

Pharmacoeconomic studies have been conducted. According to the results of ABC analysis, the drugs according to the INN Ademetionine code A16AA02 for the pharmacotherapy of comorbid vasculitis with cryoglobulinemic syndrome were distributed in descending order of value.

It is noted that the cheapest, with a high level of affordability at a price (category C) is one drug (Hep-art).

The most expensive, with a low level of economic availability in category A are 4 drugs according to INN Ademetionine (Lyophilized powders for solution for injection and Enteric tablets).

The average price for category $\mathrm{C}$ and the average level of availability was recorded for two drugs: Heptral and Rehol.

According to the results of VEN-analysis, it was calculated that the drugs in category $\mathrm{E}$ (Essential) accounted for the largest number of doctor's appointments and the cost of therapy $(100 \%)$. It is estimated that the niche of the A / E matrix took $80.34 \%$. This niche includes the most expensive and necessary drugs for the pharmacotherapy of comorbid vasculitis with cryoglobulinemic syndrome.

In terms of priority for comorbid vasculitis with cryoglobulinemic syndrome developed a matrix of consolidated $\mathrm{ABC} / \mathrm{VEN}$ analysis of drugs according to INN Ademetionine code A16AA02

The results of the study provide an opportunity to make administrative and managerial decisions in the detection of comorbid vasculitis with cryoglobulinemic syndrome to improve the use of drugs in health care facilities.

\section{References}

ATC-classification, 2020. Compendium on-line. Retrieved from: http://compendium.com.ua/atc (accessed 20.02.2021)

Beketova T.V., Blank L.M., Lila A.M. (2019) COVID-19 in a patient with ANCA-associated systemic vasculitis, receiving anti-B cell therapy (rituximab). Rheumatology Science and Practice. Retrieved from: https://rsp.mediar-press.net/rsp/article/view/2889?locale=ru_RU\# (accessed 04.02.2021)

Fellner C. (2016) Biologics will pump up the Vasculitis Market. Pharmacy and Therapeutics, vol. 41, no. 4, pp. 258-260. Retrieved from: https://pubmed.ncbi.nlm.nih.gov/27069346/ (accessed 21.12.2020)

Hayduchok I.G., Shapovalova V.O., Shapovalov V.V. (Jr.), Shapovalov V.V. (Jr.) (2020) Control regime of antibacterial drugs for pharmacotherapy of coronavirus disease (COVID-19) among 
patients with dual disorders. An information letter about innovations Ukrmedpatentinform of the Ministry of Health of Ukraine. Kyiv: Ukrmedpatentinform of the Ministry of Health of Ukraine, no. 230-2020, 6 p.

Hayduchok I.G., Shapovalova V.O., Shapovalov V.V. (Jr.), Shapovalov V.V. (2020). Control regime of drugs for pharmacotherapy of coronavirus disease (COVID-19) in patients with systemic diseases. An information letter about innovations Ukrmedpatentinform of the Ministry of Health of Ukraine. Kyiv: Ukrmedpatentinform of the Ministry of Health of Ukraine, no. 225-2020, 6 p.

Hayduchok I.G., Shapovalova V.O., Shapovalov V.V. (Jr.), Shapovalov V.V. (2021) Control regime of drugs for pharmacotherapy vasculitis of Shenlein-Genoch. An information letter about innovations Ukrmedpatentinform of the Ministry of Health of Ukraine. Kyiv: Ukrmedpatentinform of the Ministry of Health of Ukraine, no. 64-2021, 7 p.

International Guideline 00449 (2017) Vasculitis. Retrieved from: http://moz.gov.ua/ (accessed 07.05.2018)

International Guideline 00653 (2016) Purple Shenlein-Genoch. Retrieved from: http://moz.gov. ua/ (accessed 07.05.2018)

Krivenko V. I., Krivenko V. I., Phedorova O. P., Pakhomova S. P. (2018) Systemic vasculitis in the practice of a general practitioner - family medicine. Zaporozhye, 93 p. Retrieved from: http://dspace.zsmu.edu.ua/bitstream (accessed 11.02.2021)

Kuzmina A. P. (2015) Systemic vasculitis: a diagnostic search in real clinical practice. Health of Ukraine, vol. 3, no. 40, pp. 42-44.

Mamarde A. (2016) ABC/VEN Analysis of drug store in Tertiary care hospital for year 2013-2014. American Journal of Pharmaceutical Research, vol. 6, no. 8, pp. 6439-6444.

Management Science for Health. Managing Medicines Selection (2012) Arlington: USA, pp. 161-165.

Marushko T. V. (2020) Systemic vasculitis: principles of diagnosis and treatment. Pediatrics, vol. 1, no. 52. Retrieved from: https://health-ua.com/article/46571-sistemn-vaskulti-printcipi-dagnostiki-talkuvannya (accessed 17.01.2021)

National list of basic medicines (2009) Resolution of the Cabinet of Ministers of Ukraine no. 333. Retrieved from: http://zakon.rada.gov.ua (accessed 29.03.2011)

Order of the Ministry of Health of Ukraine (2020) On approval of the twelfth issue of the State formulary of medicines and ensuring its availability. Dated 06.05.2020 no.1075. Retrieved from: https://zakon.rada.gov.ua (accessed 18.05.2020)

Shapovalov (Jr.) V. V., Gudzenko A. A., Andrieieva V. V., Shapovalova V. A., Shapovalov V. V. (2019) Experience of the USA concerning and organization of healthcare system for the pharmaceutical provision for privileged categories of citizens. Annals of Mechnikov Institute, no. 1, pp. 81-87. Retrieved from: http://www.imiamn.org.ua/journal/1_2019/PDF/13.pdf. doi: 10.5281/zenodo.2639521(accessed 24.02.2020)

Shapovalov (Jr.) V. V., Gudzenko A. A., Shapovalova V. A., Shapovalov V. V. (2020) Forensic and pharmaceutical analysis of addictive morbidity because of the use of psychoactive substances in Ukraine. Klin. inform. Telemed, vol. 15, no. 16, pp. 125-128. Retrieved from: http://kit-journal.com.ua. doi.org/10.31071/kit2020.16.02 (accessed 22.01.2021)

Shapovalov (Jr.) V. V., Shapovalova V. O., Andrieieva V. V., Shapovalov V. V. (2019) Experience of Great Britain in organization of healthcare system for pharmaceutical provision with medicines for privileged categories of citizens. Health of society, vol. 78, no. 1, pp. 36-40. doi: 10.22141/2306-2436.8. 1.2019.172617 
Shapovalov (Jr.) V., Gudzenko A., Komar L., Butko A., Shapovalova V., Shapovalov V. (2017) Concerning the importance of forensic and pharmaceutical researches to improve patients accessibility to medicines. Pharmacia, vol. 65, no. 2, pp. 23-29.

Shapovalov (Jr.) V., Gudzenko A., Shapovalov V., Shapovalova V. (2018) Organizational and legal aspects of the use of pharmacoeconomic analysis of multivitamin complexes for pharmaceutical provision of military personnel. The Pharma Innovation Journal, vol. 7, no. 10, pp. 166-169.

Shapovalov (Jr.) V., Gudzenko A., Shapovalova V., Osyntseva A., Shapovalov, V. (2017) Forensic and pharmaceutical study of the presence of a causal link between the degree of alcohol abuse and qualification level of the respondents. Pharmacia, vol. 66, no. 3, pp. 31-39.

Shapovalov (Jr.) V., Zbrozhek S., Gudzenko A., Shapovalova V., Shapovalov V. (2018) Organizational and legal analysis of the pharmaceutical provision for the most common diseases of society. International Journal of Pharmaceutical Sciences Review and Research, vol. 51, no. 18, pp. 118-124.

Shapovalova V. O., Zbrozhek S. I., Shapovalov (Jr.) V. V., Shapovalov V. V. (2021) Forensic pharmacy: some risk factors in the formation of addictive health disorders. Acta Scientific Pharmaceutical Science, vol. 4, no. 1, pp. 7-12. doi: 10.3180 / ASPS.2020.05.0651

Shapovalova V. O., Zbrozhek S. I., Shapovalov V. V. (Jr.), Shapovalov V. V. (2020) Coronavirus disease pandemia 2019: growth of epidemic dangers. Acta scientific pharmaceutical science, vol. 4, no. 7, pp. $61-68$.

Snow John (2005) Logistics Indicators Assessment Tool. Arlington: United States Agency for International Development, $121 \mathrm{p}$.

Vasculitis. Five drugs to control this mysterious blood vessel illness (2017) Retrieved from: https://health.clevelandclinic.org/4-medicines-help-you-manage-the-mysteries-of-vasculitis/ (accessed 19.02.2021) 